\title{
EVALUATING SPECIAL EVENTS: MERGING TWO ESSENTIAL APPROACHES
}

\author{
LARRY DWYER*†‡ AND PETER FORSYTH§ \\ *School of Business, University of Technology, Sydney, Australia \\ †Griffith Institute for Tourism (GIFT), Griffith University, Nathan, Australia \\ ¥ Faculty of Economics, Ljubljana University, Ljubljana, Slovenia \\ $\S$ Monash University, Melbourne, Australia
}

\begin{abstract}
In special event evaluation, given the shift away from standard economic impact analysis based on input-output modeling, increased attention is being paid to the roles that computable general equilibrium modeling (CGE) and cost-benefit analysis (CBA) can play in event evaluation. This article analyzes the strengths and limitations of CGE and CBA in the context of event assessment. A "hybrid" approach is outlined which includes a role for the advantages of both techniques to be included in the evaluation process. The issues addressed are theoretically important for both impact and benefit estimation, while having significant practical implications for event assessment.
\end{abstract}

Key words: Special events; Evaluation; Economic impact analysis; Computable general equilibrium modeling; Cost-benefit analysis

Introduction

Special events are widely recognized to have a range of impacts-economic, social, and environmental. Increasingly, event assessment is used by policy evaluators such as public sector finance departments to inform policy makers whether allocating resources in support of some event is appropriate and, if so, to what extent. To make informed choices, public sector agencies increasingly demand greater rigor in evaluation techniques
(Ministry of Business Innovation and Employment, 2013; Victorian Auditor General Office [VAGO], 2007). Where public funds are used to support an event, the cost of these funds must be compared to the expected benefits. Ideally, governments should fund events only if they create net benefits, especially if the event would not otherwise take place. The problem faced by researchers is to provide techniques that give accurate results, while at the same time having practical use for the different stakeholders. 
Three main approaches to the economic evaluation of special events may be distinguished. These are: standard economic impact analysis (EIA), computable general equilibrium (CGE) modeling, and cost-benefit analysis (CBA). Despite substantial differences between these approaches, relatively little by way of rigorous examination of the theoretical aspects of evaluation of special events has been undertaken.

Standard EIA takes event-related injected expenditure to generate direct and secondary (indirect and induced) effects, leading to estimates of increases in economic activity within the host destination. Standard EIA traces the flows of spending associated with tourism activity in an economy through business, households, and government to identify the resulting changes in economic variables such as sales, output, government tax revenues, household income, value added, and employment. The relationship between injected expenditure and output, income, value added, and employment can be described by multipliers, the size of which will depend importantly upon the type of model used to estimate the impacts (Dwyer, Forsyth, \& Spurr, 2004, 2005, 2006). Over the past decade, standard EIA approaches to the economic evaluation of special events (Crompton, Lee, \& Shuster, 2001; Frechtling \& Horvath, 1999) have been heavily criticized for their use of input-output (I-O) models with unrealistic assumptions, narrow focus, exaggerated estimates of impacts, and their lack of a welfare measure to inform public policy (Dwyer, Jago, \& Forsyth, 2016; Jago \& Dwyer, 2006). In the sport management literature (Kesanne, 2005; Matheson, 2002), criticisms are made of standard EIA but there seems to be a general lack of awareness of the existence or potential of CGE modeling as a tool for resolving many problems faced in evaluation of sports events.

Increasingly, event researchers now employ CGE models for event evaluation, particularly for larger events (Bohlmann \& van Heerden, 2008; Li, Blake, \& Thomas, 2013; Madden, 2006). CGE models represent best practice in assessing the economywide economic impacts of changes in visitor expenditure (Burfisher, 2011; Dwyer, 2015a, 2015b). Like EIA, CGE models simulate the effects of an event-related expenditure shock on economic variables, such as GDP, prices, wages, income, employment, and investment in the event destination. Unlike standard EIA, CGE models recognize that the greater resource requirements associated with event-related expenditure are likely to result in lower resource use, and output, in other areas of economic activity. Prices for goods and services used as inputs including wages, may be bid up, discouraging production of other goods and services. For open economies with flexible exchange rates, increased event-related spending by foreign visitors puts upward pressure on the exchange rate, discouraging exports and economic activity in import-competing sectors.

The third approach, CBA, is a comprehensive economic appraisal technique that compares all the benefits associated with an event with the associated costs present and expected in the future. The objective of CBA is to assess if a destination economy is better or worse off due to hosting the event, estimating the community welfare effects in monetary (e.g., dollar) units (Boardman, Greenberg, Vining, \& Weimer, 2011; Fuguitt \& Wilcox, 1999). A welfare effect is simply any cost or benefit experienced by a member of the relevant community. CBA is concerned with measuring the change in all sources of economic welfare, whether occurring in markets or as implicit values. These include benefits and costs experienced by consumers and producers of the event(s), as well as by other members of the community who may be neither consumers nor producers of these events but who, as thirdparty participants, nevertheless experience the costs and benefits (Dwyer, 2012). For a special event to be socially acceptable, the sum of the (social and private) benefits must exceed the sum of the (private and social) costs to society, and represent the best use of limited funds, when alternative calls on these funds exist. Studies employing CBA for event evaluation include V8 racing cars (ACT Auditor General, 2002); Eurovision (Fleischer \& Felsenstein, 2002); Vancouver Winter Olympics (Shaffer, Greer, \& Mauboules, 2003); Melbourne Formula One Grand Prix (VAGO, 2007).

Despite its solid grounding in economic theory and applied welfare economics, CBA has not received the attention that it deserves, either in theoretical discussion of event evaluation or in event assessment exercises (Abelson, 2011; 
Dwyer, 2012). This omission is intriguing, given that CBA takes serious account of resident values in event assessment in contrast to EIA and CGE approaches which, with few exceptions (e.g., Blake, 2005), treat resident expenditure as simply "transferred money" having no economic welfare effect.

The primary objective of this article is to provide guidance to researchers and policy makers as to the relative advantages and limitations of the two major approaches to evaluating special events-CGE modeling and CBA-and to explore ways in which the advantages of each approach can be combined in a synergistic way. Historically, an important reason for treating CGE and CBA as entirely separate approaches is that CBA is a partial equilibrium approach to event assessment while CGE represents a general equilibrium approach. However, the widespread use of neoclassical microfoundations for general equilibrium modeling suggests that this may be a time for reappraisal of practice. Newer CGE models, with welfare functions, address some of the earlier concerns about use of such models to inform policy decisions, including the extent of public support for the holding of an event (or events) (Blake, 2005). It is argued herein that if this attempt to merge aspects of the two approaches is successful, it promises to transform the event assessment literature both in its theoretical orientation and in stakeholder "best practice" evaluation.

The structure of the article is as follows. Section two identifies the essential elements of both approaches in the context of their application to assessment of the same large event-the 2005 Formula One Grand Prix, held in Melbourne, Australia. Section three discusses the main differences between the CGE and CBA approaches as well as identifying some common elements. Section four outlines options for event evaluation including an "ideal" approach that draws upon a detailed CGE model, but also on CBA approaches to handle aspects that are not addressed by the model. A second-best approach is also outlined involving an assessment strategy given certain data limitations. The article concludes with a discussion of the policy implications of the recommended approach and an agenda for further research in event assessment.

\section{Essential Elements of CGE and CBA:} Assessment of a Formula 1 Grand Prix

A useful way to illustrate the differences between CGE and CBA in event assessment and to provide a basis for our arguments below is to consider how each technique may be used to assess the same event and what types of outcomes result. This issue is of particular interest to the city of Melbourne, which is one of many cities worldwide that uses special events to leverage its destination marketing strategy (Richards \& Colombo, 2017) In 2007, the VAGO (2007), addressing the problem of the ideal approach to the assessment of larger scale events, commissioned both CGE modeling as well as a CBA of the 2005 Formula One Grand Prix, held in Melbourne.

CGE simulations of the race found that eventrelated expenditure of $\$ 58.4$ million injected into the State of Victoria from interstate and overseas generated positive macroeconomic consequences, with real gross state product (GSP) up by $\$ 62.4$ million, increased state taxes \$3.5 million, and 400 new jobs in the State (full-time equivalents). In contrast, a CBA of the same event estimated total costs to be $\$ 69.8$ million, compared to total benefits of $\$ 63.1$ million, yielding a net loss (costs exceed benefits) of \$6.7 million (VAGO, 2007).

Although the benefits and costs and economic impacts were all valued in 2005 dollars, unfortunately no attempt was made to analyze the sources of the differences in the two measurement techniques. Thus, stakeholders are left with two apparently conflicting results from the same event-positive net impacts from CGE modeling versus negative net benefits from the CBA. In seeking to resolve this seeming conflict we first provide a brief overview of the key elements of each technique applied to assessment of the Grand Prix.

\section{CGE Modeling}

The CGE model used in the Grand Prix evaluation comparison study was the Monash Multiregional Forecasting (MMRF) Model (Adams, Dixon, Parmenter, Giesecke, \& Horridge, 2010). MMRF is a multiregional CGE model of Australia's eight regional economies_-six States and two Territories. MMRF generates outputs at the macroeconomic 
(state and national) level by industry. At the state level, there is detailed modeling of the behavior and interactions of five types of economic entities: industries, investors, households, governments, and foreigners. MMRF can be configured to run in one of two modes: comparative static mode or recursive dynamic (year to year) mode. In comparative static mode, as employed in the assessment of the economic impacts of the Grand Prix, MMRF indicates the effects of the specified policy change over a short-run or long-run time span, depending on the closure chosen.

The fundamental assumptions employed in the analysis of the Grand Prix are that labor is mobile between state economies, that real public consumption expenditure is assumed to move with real private consumption expenditure in response to the activity associated with the Grand Prix, that real consumption is assumed to change in line with changes to real income available to residents, and that industries that benefit from the Grand Prix (e.g., accommodation sector) will receive increased capital (at a fixed rate of return) compared with industries that do not benefit (VAGO, 2007).

Figure 1 displays the main types of economic impacts resulting from the CGE simulations of the 2005 Grand Prix, and their direction. Sensitivity analysis was applied to estimate high, medium, and low effects. The size of these depended upon assumptions regarding the amount of residentdisplaced expenditure on other goods and services and on factor constraints and their impacts on prices and wage rates. The assumptions made affected the size rather than the direction of the changes in economic variables.

\section{Direct Impacts}

The direct impacts comprise the event-related expenditure injected into the event location (the state of Victoria). Injected expenditure comes from several sources-visitors, media, participants, sponsors, etc. Consistent with best practice event assessment, it is assumed that all expenditure by Victorians on Grand Prix-related goods and services is sourced by reducing expenditure in equal amounts on other goods and services (Jago \& Dwyer, 2006). Thus, the estimated gross expenditure associated with the event was adjusted to eliminate the expenditure of residents (because it is not injected expenditure). Also, not counted was the expenditure of time switchers and casuals (event attendees who did not visit Melbourne specifically for the Grand Prix). However, the additional expenditure of visitors who prolonged their stay in Victoria because of the event (extenders) is added to the injected expenditure total.

In staging the Grand Prix, the organizer makes "out of state" purchases (leakages from Victoria) and receives revenues from other states (inflows to Victoria). Sponsorships from external sources add to the injected expenditure while monies leaking out of the state economy (the net import expenditure arising from Grand Prix operations) must be deducted from the total injected expenditure amount.

Surveys revealed that many residents departed the state to avoid the Grand Prix, diverting expenditure away from the state (repulsion effect). The size of any such effect depends importantly on expectations regarding the social and environmental effects of the event.

\section{State-Wide Economic Effects}

The extent to which the extra expenditure on goods and services in Victoria results in extra GSP in the short run depends on how much is met by additional local production (due to spare capacity or by employing extra labor) and how much is met by imports of goods and services from outside Victoria. As shown in Figure 1, the macroeconomic consequences for Victoria are positive with real GSP up by $\$ 62.4$ million, and real consumption increasing by $\$ 16$ million. The number of new jobs created is estimated to be 400 . Increases are experienced in investment, private, and public consumption and net taxation revenues to the state. The overall increase in foreign exports from Victoria is less than the direct stimulus to Grand Prix exports, due to the real appreciation of the Australian dollar exchange rate, which puts downward pressure on other exports from Victoria.

\section{Nationwide Economic Effects}

The modeling indicates that the Grand Prix was associated with a substantial shift of resources and 


\begin{tabular}{|c|c|}
\hline \multicolumn{2}{|c|}{$\begin{array}{l}\text { Direct Impacts on State (Smillion) } \\
\text { - Expenditure by additional non- local tourists } \\
\text { - Expenditure by visitors prolonging stay } \\
\text { - Expenditure by the media } \\
\text { - } \text { Sppenditure by drivers, teams and officials } \\
\text { - less outflows from organiser budget } \\
=\text { less repulsion effects } \\
=\text { Total Net Injected Expenditure (Total Direct Impact) }\end{array}$} \\
\hline \begin{tabular}{|l|} 
State-wide economic effects (Smillion) \\
\end{tabular} & Nationwide economic effects (\$ million) \\
\hline $\begin{array}{llc}\text { - } & \text { Gross state product (GSP)+ } \\
\text { - } & \text { Private investment } & + \\
\text { - } & \text { Private consumption } & + \\
\text { - } & \text { Public consumption } & + \\
\text { - } & \text { State tax receipts } & + \\
\text { - } & \text { Employment positions } & +\end{array}$ & $\begin{array}{l}\text { - } \text { Gross domestic product (GDP) + } \\
\text { - Private investment } \quad- \\
\text { - Private consumption } \quad- \\
\text { - Public consumption } \quad \text { National tax revenue } \quad+ \\
\text { - } \text { Foreign export volume }+ \\
\text { - } \text { Current account balance - } \\
\text { - Employment positions } \quad 0\end{array}$ \\
\hline $\begin{array}{l}\text { Industry Effects } \\
\text { Gains to all industries within state } \\
\text { Relatively large increases to output and } \\
\text { employment (\%) occur in air passenger services, } \\
\text { road passenger services, and hotels, cafes, } \\
\text { accommodation }\end{array}$ & \begin{tabular}{l}
\multicolumn{1}{c}{ Industry Effects } \\
Some industries will experience loss of output in \\
rest of Australia \\
Key industries impacted negatively in other states \\
are iron and steel industry, food drink and \\
tobacco, ship charter, and iron ore.
\end{tabular} \\
\hline
\end{tabular}

Figure 1. CGE analysis of 2005 Formula One Grand Prix, Melbourne. Source: Author construction based on VAGO (2007, section B). + indicates positive effect and - indicates a negative effect.

economic activity from the rest of Australia (RoA) to Victoria, reducing GSP in other states by $\$ 60.5$ million in total. Overall, the event generated (a small) \$1.9 million increase in GDP in Australia with negative effects on national investment and consumption (private and public). Overall, the event resulted in a slight increase in tax revenues collected in Australia. The fall in consumption leads to a fall in real national domestic "absorption" (the sum of consumption, investment, and government expenditure) relative to real gross domestic demand. This allows for a small improvement in Australia's trade balance. Despite the trade-account improvement, the current account balance still deteriorates relative to its base case value. Nationally, there is no change in total employment resulting from an annual event since the long-run national employment is determined by demographic factors (birth rates, death rates, etc.), which are unaffected by the Grand Prix. This was a time of very low unemployment in Australia. These results contrast with those of standard EIA, which always have positive effects on jobs both in the short and long run.

\section{Industry Effects}

Most industries in the state increase their output (relative to base case values) with no industry suffering a decline. This reflects the presence of positive-induced income effects within the State (i.e., higher GSP leads to more consumer spending), which ultimately benefits all industries. The industries that gain most from the Grand Prix are those that directly supply goods and services to visitors. The key industries in Victoria that experienced relatively high increases to employment 
(in percentage terms) arising from the Formula 1 Grand Prix are air passenger services, road passenger services, and hotels, accommodation, cafes.

For RoA, the Grand Prix crowds out activity in various other industries, because it diverts expenditure into Victoria from elsewhere in Australia. Additionally, the negative effects of real exchange rate appreciation erode the price competitiveness of traded-goods industries throughout Australia. The key industries impacted negatively in respect of output and value added in other states are food, drink, and tobacco, hotels, cafes, accommodation, iron and steel, and other services.

\section{Cost-Benefit Analysis (CBA)}

Applied welfare analysis in the form of CBA seeks to answer the question: when is society's welfare improved by holding the event, given the investment alternatives under consideration? Benefits are measured as the additional consumer, producer, and labor surplus of a given option over the "do nothing" or "no event" case. Costs are measured by "opportunity cost"-what people or a society give up by investing capital and employing workers in event-related activities as opposed to the best alternative.

Figure 2 lists the types of costs and benefits associated with the 2005 Formula One Grand Prix.

\section{Costs}

In general, the amount spent on producing the Grand Prix is the cost of resources employed. The cost of employing capital, land, and labor for the event is the value of what those economic resources could have produced in their best alternative use. Unless the event employs capital, land, and labor that would otherwise be unemployed, the full construction and operating cost of the event is a cost in the CBA. Event construction and operation costs according to the accounts of that Australian Grand Prix Corporation (AGCP) were $\$ 68.1$ million. Other event-related costs incurred by government agencies such as road agencies, police, ambulance, fire brigade, and state emergency services, totaling \$0.5 million, were estimated from government accounts. Community costs can include items such as disruption to business and resident lifestyles, loss of park uses and amenity, traffic diversion and congestion, road accidents, crime, litter, noise, crowding, property damage, environmental degradation, vandalism, air/water pollution, and carbon footprint. Effects that cannot reasonably be quantified in monetary terms should not be ignored in a CBA. If the externalities are unable to be quantified, they should at least be identified and explained to decision makers. In the CBA study that was undertaken, temporary loss of park uses and amenity, traffic diversion, and congestion were estimated at $\$ 1.2$ million by imputed valuation concerning effects on property values and costs of travel time (VAGO, 2007).

Volunteers who generally take leave from their employment to provide services at the event are not included in these costs. Although there would be a cost to the community through their involvement in the event in terms of lost production, it is difficult to provide reliable cost estimates in most situations.

\section{Benefits}

Four main types of benefits to Victorians from the Grand Prix were estimated in the CBA.

Visitor and Sponsor Payments to the Event Organizer, AGPC. The ticket sales and sponsor revenue received by the AGPC (exclusive of goods and services tax payments) are a benefit to the Victorian taxpayer in that they offset the costs incurred in staging the Grand Prix and reduce the size of the Victorian Government subsidy to the Grand Prix. Visitor and sponsor payments to the AGPC, from its accounts, were \$52.4 million.

Consumer Surpluses to Households. For many events, the price that residents are willing to pay to attend the event exceeds what they are required to pay to attend. Whenever the price that event attendees are willing to pay exceeds what they are required to pay (which could be zero), they experience a net gain or "consumer surplus," implying a net gain to residents from holding the event. Assumed central case, based on an earlier study by ACT Auditor General (2002), was that consumer surplus was $10.8 \%$ of ticket sales to Victorians. This yielded a benefit estimate of \$3.4 million. 


\section{Costs}

- Capital expenditures on event-related infrastructure

- Operating expenditures (e.g., event management and staging, recurrent engineering, marketing/ promotion and catering, administration $\$ 68.1 \mathrm{~m}$

- Other event-related costs incurred by government agencies $\$ 0.5 \mathrm{~m}$

- Social and environmental costs $\$ 1.2 \mathrm{~m}$

Total Costs $=\$ 69.8 \mathrm{~m}$

\section{Benefits}

- Payments to event organizer (AGPC). Includes ticket revenue, sponsorship and advertising revenue and media payments. $\$ 52.4 \mathrm{~m}$.

- Consumer surpluses of local households derived from attending the event. $\$ 3.4 \mathrm{~m}$

- Consumer surpluses of local households from attending associated offsite events/activities (e.g. satellite events, public screenings and off-site entertainment such as street parades). $\$ 1.9 \mathrm{~m}$

- Other benefits to local households from indirect enjoyment of the event. These include the pride and excitement that many residents derive, irrespective of any direct or indirect participatory benefits

- Business (producer) surplus -returns to locally owned capital associated with the event. $\$ 3.7 \mathrm{~m}$

- Labor surplus - the net benefits associated with event-related employment, after compensation for work undertaken and taxes paid. $\$ 1.7 \mathrm{~m}$

Total Benefits $=\$ 63.1 \mathrm{~m}$

Figure 2. Cost-benefit analysis of 2005 Formula One Grand Prix. Source: Based on VAGO (2007, section A). The estimates receive more detailed justification in the report.

Other Consumer Benefits (e.g., Benefits of Participating in Related Off-Site Events). Indirect participation at related (off-site) activities (processions, displays, entertainments) indicates that residents also derive benefits from these activities. Because they would not exist in the absence of the event, they must be counted as benefits to residents in addition to the consumer surpluses from event attendance itself. This was estimated to be $\$ 1.9$ million, with assumed $\$ 10$ consumer surplus for each of 190,000 residents of Victoria who participated in off-track events.

Benefits Accrue to Residents who may not Attend any Event-Related Activities. Residents may attach value to the positive experiences that an event brings to others, whether users or nonusers. The values that others are perceived to attach to an event can, in principle, cover a substantial range including symbolic, educational, aesthetic, political, spiritual, lifestyle, prestige, community pride, social cohesion, etc. These nonuse values may well comprise an important part of the social valuation of an event (Dwyer \& Forsyth, 2017), but were not estimated in the Grand Prix CBA.

Business (producer) surplus (loss) comprises the net returns to locally owned capital associated with the event. This is the difference between the value of the expanded output and the cost of the factors of production where their cost reflects their value in alternative uses. The extent of any 
business surpluses accruing to Victorian businesses depends crucially on whether there is spare capacity at the time of the Grand Prix. The CBA estimated business surplus accruing to Victorian businesses during the event to be $\$ 3.7$ million based on earlier research by Dwyer et al. (2005), that calculated a business surplus of $13.5 \%$ of international and interstate expenditure, other than on ticket purchases.

Unemployed or underemployed workers can be hired on a casual basis to meet the extra demand for goods and services associated with an event. Labor surplus is the difference between the wage received and the so called "transfer payment" that they would receive in alternative employment. This recognizes that workers, as an input to the business activity that may be stimulated by an event, may make a surplus over the wage for which they would be willing to work. In the CBA of the Grand Prix, labor surpluses were estimated at $\$ 1.7$ million, based on research by Dwyer et al. (2005) that $3 \%$ of the expenditure derived from international and interstate visitors other than on tickets is a surplus, adjusted for crowding out.

More detailed discussion of the formulae for estimating the surpluses that are likely to accrue to businesses and labor because of holding an event can be found in Dwyer and Forsyth (2009) and Dwyer et al. (2016).

Social and environmental benefits (and costs) that are known to exist but cannot be precisely identified and accurately quantified, let alone valued are referred to as "intangibles." For example, these might include the capacity of special "themed" events to improve "destination image," "branding," or "community pride." A CBA should attempt to value whatever can be quantified and valued reliably within the resource constraints of the situation (Dwyer, 2012). The CBA of the Grand Prix did not measure the follow-on benefits of future visitors to the tourism industry (brand benefit) or any ongoing (legacy) benefits from construction of assets for the event. To assess whether there was a long-run tourism effect, the outcomes of the Grand Prix as a marketing instrument would need to be evaluated. The CBA of the Grand Prix also omits estimation of the benefits and costs arising from distortions in the economy arising from the presence of terms of trade effects, market power, taxes and subsidies, government revenue effects, labor market effects, foreign exchange effects, and the existence of externalities (Dwyer \& Forsyth, 1993). These types of distortions, which exist to varying degrees in all economies, affect the net benefits from visitor expenditure. They are unlikely to have had much influence on the bottom-line net benefit assessment of this event but may be relevant to the assessment of other large events depending on the destination.

In assessing the net benefit from the 2005 Australian Formula 1 Grand Prix, where reliable information was not available, best estimates and proxies were used as a substitute. The analysts applied a sensitivity analysis to the estimates of Victorian consumer surplus and Victorian business and labor surpluses to assess whether arguable ranges of the estimates for these items would make a significant difference to the overall net benefit. The estimated net loss ranged between \$3.0 million and \$10.4 million. Best estimates were that the costs of producing the $2005 \mathrm{Grand}$ Prix event were $\$ 69.8$ million, while the estimated benefits were $\$ 63.1$ million. This yielded an estimated net benefit (cost) of \$-6.7 million for the items included in this CBA.

\section{Essential Differences Between CGE and CBA}

The event assessments outlined above, using either CGE and CBA, are representative of the main elements of each technique. Figure 3 summarizes the key types of information included and excluded by the CGE and CBA approaches to event assessment.

Although there are several points of difference between CGE and CBA approaches to event evaluation, it will be argued below that in several respects, the two techniques are not as distinct as Figures 1, 2, and 3 and the research literature might suggest. To the extent that the best aspects of each approach can be preserved in event assessment, progress toward the formulation of a hybrid model can be made.

\section{The Objective of the Evaluation}

The objectives of the two assessment techniques are quite different. Historically, CGE (without a welfare measure) has been used to determine the economy-wide economic impacts of the injected expenditure associated with a special event. In 


\begin{tabular}{|c|c|}
\hline CGE Approach & CBA Approach \\
\hline 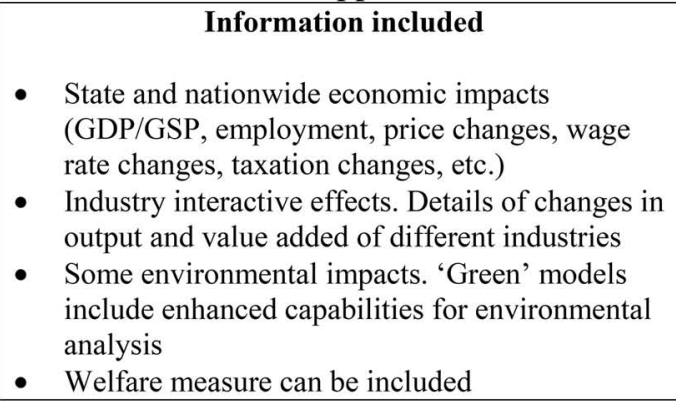 & \begin{tabular}{ll}
\multicolumn{1}{c}{ Information included } \\
- & Resident consumer surpluses (direct and \\
indirect) \\
- & Business surpluses \\
- & Labor surpluses \\
- & Social costs and benefits \\
\end{tabular} \\
\hline $\begin{array}{l}\text { Information excluded } \\
\text { - } \quad \text { Resident event-related expenditure (treated as } \\
\text { 'transferred expenditure, but can be included) } \\
\text { - } \quad \text { social impacts (except for job creation) } \\
\text { - } \quad \text { (some) environmental impacts } \\
\quad \text { 'Intangibles' (destination branding value etc.) }\end{array}$ & \begin{tabular}{l}
\multicolumn{1}{c}{ Information excluded } \\
- $\quad$ event impact on economic variables (GSP, \\
- Tourism Industry Output etc.) \\
- $\quad$ industry interactive effects \\
- Economy wide externalities (e.g. carbon \\
- $\quad$ Distributional effects \\
- Induced employment numbers \\
- 'Intangibles'
\end{tabular} \\
\hline
\end{tabular}

Figure 3. Types of information included and excluded on the two approaches.

contrast, CBA attempts to estimate the net benefits to residents associated with the event (the surpluses generated by the event accruing to consumers and wider community members, businesses, and workers).

In its focus on injected expenditure as the source of economic impacts, CGE modeling (and of course standard EIA) typically excludes resident values of events from the assessment process, treating resident event-related expenditure merely as "transferred expenditure" (Dwyer et al., 2016). How this exclusion of resident willingness to pay for event attendance harmonizes with views of the importance of events to local communities is generally ignored by theorists and practitioners alike. If the CGE modeling is to estimate the net benefits to society from holding the event, it is necessary for the technique to include a welfare measure of the net benefits and costs. Destinations that neglect the importance of special events to their own residents cannot be expected to make informed decisions regarding either an appropriate "events budget" or appropriate levels of funding for particular events that may be proposed.

In contrast, in CBA the estimation of resident benefits is central to the assessment exercise.
However, there is no accepted way of handling injected expenditure with CBA, and this technique does not provide any means of measuring event-related economic impacts. This is a serious limitation of CBA, because many events are targeted towards visitors to a region and visitor expenditure generates economic impacts, including employment creation (ACT Auditor General, 2002). Although estimation of economic impacts does not address the bottom-line question as to whether the destination gains from the event overall, this information provides useful knowledge to policy makers and event organizers regarding the effects of alternative resource allocation, policy, management, or tourism development strategies.

\section{Partial Versus General Equilibrium}

CBA is a partial equilibrium approach. Partial equilibrium analysis examines the effects of policy action in creating equilibrium only in that particular sector or market that is directly affected, ignoring its effect in any other market or industry. Thus, CBA typically measures only the surpluses associated with direct or "first-round" effects of some expenditure shock to a destination. 
However, there are likely to be impacts elsewhere in the economy that flow from the event and that should be considered in costs and benefits measurement (Dwyer et al., 2016). The statewide, nationwide, and industry effects set down in Figure 1 are the "bottom-line" effects of a general equilibrium approach that accounts for changes in the relevant economic variables, allowing for feedback effects between different sectors. In principle, this approach captures all the event-related effects, direct and indirect. By setting up the economic conditions whereby each market, sector, and household reacts to changes in the economy, a CGE approach can model a variety of possible scenarios to fit different event contexts (Dwyer, 2015a). Advances in theoretical and computable general equilibrium modeling have brought their conceptual foundations more into line with standard microeconomic constructs. This has reduced what has been, until recently, the theoretical and empirical gap between welfare measurements using either a partial or a general equilibrium approach (Farrow \& Rose, 2018; Hayashi, 2017). Given their greater flexibility in identifying the indirect effects of demand shocks to an economy, CGE models have been advocated as a form of general equilibrium CBA (Broecker \& Mercenier, 2011).

\section{Taxes and Subsidies}

An event is both a buyer of inputs and a supplier of outputs. In the presence of taxes and subsidies for construction and operation of event-related facilities, market prices may not accurately measure the opportunity costs, or shadow prices, of inputs or outputs. To the extent that event facilities are financed by distortionary taxes that cause deadweight loss, this excess burden must be considered in estimating the net benefits of the event. When there is expenditure by a foreign tourist who pays a market price above the shadow price, there is a net benefit to the host country. However, additional visitor expenditure used to purchase goods or services that are subsidized by the government imposes additional costs on the host economy, because visitors pay less than the cost of supplying the services to them. Shadow pricing can be used in CBA to account for some of the more important distortions.
In the Grand Prix case, as shown in Figure 2, the CBA did not shadow price the costs to government agencies that effectively "subsidize" the staging of the event, nor the expenditures of visitors. In circumstances where this is undertaken, it is important that industry interactive effects first be determined to understand the bottom-line effects that the event may have on composition of industry in the destination.

\section{Adding a Welfare Measure to CGE}

Economists know that increased output is a benefit only in so far as it produces surpluses to capital, land, or labor. Prices do not always reflect full benefits from consumption or full costs of production and thus may be unreliable as measures of the well-being of an economy. Because changes in output, GDP/GSP, income, and related economic variables resulting from the holding of an event reflect unadjusted market prices, they are an inaccurate measure of the real net benefits accruing to the destination (Dwyer, 2012).

The model employed in the CGE technique comparison above does not include a welfare measure and so, despite producing "positive" economic impacts, cannot inform event stakeholders as to whether the state or nation has "gained" from the holding of the Grand Prix. Essentially, this would involve estimating the value of the gain in economic activity less the cost needed to enable this extra activity (Dixon \& Rimmer, 2002; Dwyer et al., 2016). To enable the addition to GDP/GSP generated by a special event, inputs are neededadditional labor must be hired, additional capital must be made available, more land will be alienated, and more natural resources will be used up, with attendant social and environmental costs.

A welfare measure is needed to give CGE simulations clear policy significance. The building blocks needed to develop a welfare measure are normally already present in CGE models-there are demand functions from which consumer's surplus can be calculated, cost and production functions, and information about distortions such as taxes (Dwyer, 2015a). The three metrics in common use are: equivalent variation (EV), compensating variation (CV), and Marshallian surplus. These are usually developed in detail for consumers but 
can be applied to producers and factor suppliers (Just, Hueth \& Schmitz, 2004). For those CGE models that include a welfare measure (Blake, 2005; Farrow \& Rose, 2018), the results for changes in welfare are listed in the same way as results for changes in GDP, consumption, and other variables. If a CGE model is to be used to estimate the welfare gain or loss from an event, it is highly desirable that the event be modeled by as a new "industry," buying inputs and selling to consumers, both local and from outside the destination. This would involve setting up a submodel with an event "industry," to enable an accurate estimate of the gains and losses. In this way, the results from the CGE model may be directly compared to those of a CBA.

\section{Distributional Issues}

Many CBAs and CGE studies do not consider distributional effects. Often this is because these effects are not regarded as important by decision makers. The CGE modeling of the Grand Prix identifies industry "winners" and "losers," but does not drill further down to assess the income gains and losses to occupational groups or resident groupings by location The CBA does not address distributional effects. Where distributional issues are identified, the most common approach is to summarize them for the final decision maker (Boardman et al., 2011).

Although CGE models can measure both initial and ultimate incidence of event-related expenditure on the community, a CBA can only handle initial incidence. As stated above, CBA is a partial equilibrium approach, which does not capture the indirect economy-wide effects of the event. Thus, if distributional effects are regarded as relevant, it is not feasible to rely on a CBA as the sole evaluation technique. Decision makers need to know the ultimate incidence of the event impacts which, typically, will be quite different from the first-round effects. CGE models that have information about different income groups or other groups of interest can be used to estimate how diverse groups are affected by the event. Even if the primary evaluation technique is CBA, a CGE approach can be used as a backup to explore distributional questions.

\section{Employment Issues}

A special event is most likely to generate jobs when local unemployment is high or other local resources are idle (Boardman et al., 2011). A CGE model can estimate the impact of an event on employment numbers if it has a flexible labor market. This assumption was made in the CGE modeling of the Grand Prix summarized in Figure 1. The potential for extra employment and business income in Victoria comes from the expenditures of interstate and overseas visitors to the Grand Prix. The projected increase in full-time employment related to the Grand Prix was estimated conservatively at 400 for the state, but zero for the nation (employment gained in Victoria is assumed to be offset by employment lost elsewhere in Australia).

A CGE model can also provide detailed information about changes in employment numbers in different industry sectors. However, standard CGE modeling does not have a means of valuing new jobs created except if it counts the jobs as the use of a resource whose price is the wage rate. Recently, the theory of the shadow wage has carried over to the CGE approach (Farrow \& Rose, 2018). A CGE model with a welfare measure can have a shadow wage, and if there is existing unemployment in the economy the shadow wage rate can be estimated (Dwyer, 2015a).

In contrast, CBA has no means of estimating the employment-creating effects of an event. However, it does have a long tradition of using a shadow price of labor, rather than the market wage, as the appropriate cost of labor. As a rule, CBA assumes that event-related resources would otherwise be fully employed. This is most likely to be realistic of skilled labor, which is relatively mobile. If circumstances are deemed to warrant the assignment of shadow prices to the use of otherwise-unemployed resources, the rationale for making such adjustments must be carefully outlined and defended (Fuguitt \& Wilcox, 1999).

Most CGE models have a simple labor market, not well suited to exploring questions of shadow pricing of labor. Nevertheless, they can be useful in analyzing the possible sensitivities of the evaluation to alternative labor market assumptions. Taken together, the two techniques can, in principle, measure the impact on jobs and value what the jobs are worth. 


\section{Treatment of Externalities}

Within the CBA approach, substantial progress has been made in developing methods used to evaluate environmental and social impacts of demand shocks (Atkinson \& Mourato, 2008). In the CBA of the Grand Prix, as shown in Figure 2, temporary loss of park uses and amenity, traffic diversion, and congestion, were estimated by imputed valuation concerning effects on property values and costs of travel time. However, as a partial equilibrium technique, CBA cannot by itself identify the indirect impacts associated with event-related expenditure or the associated externalities.

Although CGE modeling of the Grand Prix ignored potential externalities, CGE can include submodels that measure national/global externalities such as greenhouse gas emissions (Adams, Horridge, \& Parmenter, 2000) as well as measures of local externalities (e.g., noise costs). The microeconomic literature, in its search for "plug-in values,” has developed various welfare measures using value transfer functions to consider socioeconomic or other factors (Boardman et al., 2011; Farrow \& Rose, 2018).

The extent to which a CGE model can value externalities depends on its microeconomic database and equations system. When it comes to a question of policy evaluation, the level of disaggregation is critical. Typically, the greater the degree of aggregation, the smaller the measured welfare benefit or cost (Bergson, 1973). It is very important to have as high a degree of disaggregation as feasible when using a CGE model for evaluation of externalities. Averages are seriously misleading. Developing submodels requires more data, but has become easier with new software (Dwyer, 2015a). Currently, many CGE models have the required level of disaggregation to measure economy wide externalities (Adams et al., 2000) and this capability is one of the major advantages of using a CGE model to estimate benefits and costs as compared to standard CBA. Estimates of the carbon footprint of events require CGE modeling in association with environmental accounting (Dwyer \& Forsyth, 2017)

In many cases, it may not be worthwhile extending a CGE model to incorporate some types of externalities if this would render the model unnecessarily complex for little gain. Thus, it would be difficult to model traffic congestion associated with a large event, or noise effects, or benefits from facilities that remain after the event. In principle, they could be incorporated in the model, but the easiest way of handling them is to measure and value them outside the model using established evaluation approaches such as stated and revealed preference and "benefit transfer" (Boardman et al., 2011).

Some outcomes of an event on a destination are not sufficiently well accepted or measurable to be included either in a CGE or CBA These are often referred to as "intangible" outcomes. "Intangible" benefits include such items as increased business confidence, enhancement of destination image, technology transfer, and induced tourism to the destination in the future. "Intangible" costs include social dislocation caused by facilities construction, resident hostility, and public crowding. Because there are no observable financial transactions that could be used to measure their magnitudes, these types of effects are often ignored. Nonetheless, they represent very real effects of events on a destination and need to be recognized in the overall assessment of the costs and benefits of special events to the host destination.

\section{A Hybrid Approach to Event Evaluation}

In view of the above, an "ideal" or "hybrid" approach to event evaluation would be a CGE evaluation that uses an essentially CBA approach to handle tasks such as valuing local externalities and the shadow pricing of labor. To achieve this ideal, several conditions would need to be met. The various aspects of evaluation as listed in Figures 1, 2, and 3 would need to be covered. The CGE model would need to at least: embody a welfare measure; be capable of an elevated level of disaggregation, either in the basic model or using submodels, such as an "Event" industry; be capable of measuring economy-wide externalities, such as greenhouse gas emissions; provide results for several income groups in order to address distributional consequences.

This "hybrid" approach would cover event economic impacts, net benefits, and identify stakeholder winners and losers, possessing all the advantages of both a CGE approach and a CBA 
approach because it effectively uses a CBA when needed. It is particularly well suited for impact assessment of mega-events such as an Olympics or a Football World Cup, and for many other types of large event such as a F1 Grand Prix. The approach recommended herein can play an important role in the development of frameworks for sustainable event cities (Getz, 2017). It also has substantial relevance for the local Authority Planning Perspective (Maguire \& Hanrahan, 2017), as well as approaches to event impact evaluation in general (Kwiatkowski, 2016) and sport events in particular (Kessane, 2005). There are many CGE models available in countries at national and regional level (Dwyer, 2015a, 2015b). The opportunity exists to develop a submodel to create an event industry enabling an evaluation of the benefits of special events to residents. Given the relative simplicity of the basic CGE model, readily available online, different applications can easily be developed at relatively low cost to suit the needs of various studies (Dwyer, 2015a, 2015b). That said, the less detailed the CGE model, the less information it generates regarding net benefits and distributional consequences of events.

Given the common theoretical constructs for welfare measurement used in both partial and general equilibrium models today and the evolution in computation, CGE is likely to improve relative to CBA (Broecker \& Mercenier, 2011; Farrow \& Rose, 2018; Hayashi, 2017). CGE models are evolving in analytic power and accuracy. They are now able to capture more and more effects of expenditure shocks and can be solved more easily. As they become more disaggregated, they become more accurate in measuring benefits and costs. CGE modeling of events may be expected to improve with advances in software and the ability to readily disaggregate industries and households (Dwyer, 2015a). There is greater scope to use welfare measures in CGE modeling of tourism impacts for enhanced policy relevance and event assessment is one such area. Given that government funding agencies are now demanding that event evaluation be undertaken using state of the art techniques (Ministry of Business Innovation and Employment, 2013; VAGO, 2007), it is expected that evaluation of special events will increasingly incorporate CGE modeling of the economic impacts and cost benefit analysis of the wider economic, social, and environmental effects.

\section{Conclusions}

The major aims of this article were to explore the relative advantages and limitations of the main approaches to evaluating special events and to identify a "hybrid" approach that combines the advantages of the different approaches. The need for this type of exercise arises from the pressures on public agencies to fund events and the requirement that such funding needs be justified in terms of the social return on investment. The article emphasized the importance of net benefit/welfare measures as inputs to policy formulation in the domain of special events. Both CBA and CGE are significantly more rigorous and reliable than standard EIA for event assessment. Both techniques provide approximations to the value of an event-CBA is limited in that it does not capture the general equilibrium effects of the event, and CGE is limited by the level of aggregation in any model.

Our conclusion is that a CGE model can, with suitable adaptations, handle the key aspects of the event evaluation task, while a CBA is not able to do this. For some tasks in event evaluation, particularly in measuring the impacts of injected expenditure, there seems to be no appropriate alternative other than using a CGE approach. CGE picks up effects that partial equilibrium approaches cannot, such as those resulting from distortions in markets, taxes, unpriced externalities, and nonfull employment. CGE models can be and are used to analyze distributional effects of an event. They will measure both initial and ultimate incidence of eventrelated expenditure, while CBA can only handle the initial incidence. A CGE evaluation can be adjusted to account for local externalities and to value jobs, essentially using approaches from cost benefit analysis.

The implications for the research agenda in event evaluation are clear. The "hybrid" approach proposed in this article should now be tested in studies of real-world events. Subsequent evaluations using similar approaches for other events should tailor any assumptions to the purpose, nature, and type of event. To date, much event evaluation falls well short of "best practice." An important expected 
outcome of the proposed research is a narrowing of the divide between practitioners and theorists regarding best-practice event evaluation to the benefit of all stakeholders.

\section{References}

Abelson, P. (2011). Evaluating major events and avoiding the mercantilist fallacy. Economic Papers, 30(1), 48-59.

ACT Auditor General. (2002). ACT auditor general's office performance audit report V8 car races in Canberra: Costs and benefits. Canberra, Australia: Author.

Adams P., Dixon, J., Parmenter, B., Giesecke, J., \& Horridge, M. (2010). MMRF: Monash multi-regional forecasting model: A dynamic multi-regional model of the Australian economy (General Paper No. G-223, December). Centre of Policy Studies Monash University. Retrieved from https://www.copsmodels.com/ftp/ workpapr/g-223.pdf

Adams, P. D., Horridge, J. M., \& Parmenter, B. R. (2000). MMRF-GREEN: Adynamic, multi-sectoral, multi-regional model of Australia (No. op-94). Victoria University, Centre of Policy Studies/IMPACT Centre. Retrieved from http://vuir.vu.edu.au/29298/1/op-94.pdf

Atkinson, G., \& Mourato, S. (2008). Environmental costbenefit analysis. Annual Review of Environment and Resources, 33, 317-344.

Bergson, A. (1973). On monopoly welfare losses. The American Economic Review, 853-870.

Blake, A. (2005). The economic impact of the London 2012 Olympics, Research Report 2005/5. Christel DeHaan Tourism and Travel Research Institute: Nottingham University.

Boardman, A. E, Greenberg, D. H., Vining, A. R., \& Weimer, D. L. (2011). Cost-benefit analysis: concepts and practice (4th ed., International ed.). Boston, MA: Prentice Hall.

Bohlmann, H. R., \& van Heerden, J. H. (2008). Predicting the economic impact of the 2010 FIFA World Cup on South Africa. International Journal of Sport Management and Marketing, 3(4), 383-396.

Broecker, J., \& Mercenier, J. (2011). General equilibrium models for transportation economics. In A. de Palma, R. Lindsey, E. Quinet, \& R. Vickerman (Eds.), A handbook of transport economics (Chapter 11). Cheltenham, UK: Edward Elgar Publishing.

Burfisher, M. (2011). Introduction to computable general equilibrium models. Cambridge, UK: Cambridge University Press.

Crompton, J. L., Lee, S., \& Shuster, T. (2001). A guide for undertaking economic impact studies: The Springfest Festival. Journal of Travel Research, 40(1), 79-87.

Dixon, P., \& Rimmer, M. (2002). Dynamic general equilibrium modelling for forecasting and policy. A practical guide and documentation of MONASH. Amsterdam, Netherlands: Elsevier.
Dwyer, L. (2012). Cost benefit analysis. In L. Dwyer, A. Gill, \& N. Seetaram (Eds.), Research methods in tourism: Quantitative and qualitative approaches (pp. 290307). Cheltenham, UK: Edward Elgar Publishing.

Dwyer, L. (2015a). Computable general equilibrium modelling for tourism policy-Inputs and outputs. Statistics and TSA Issues Paper Series. Madrid, Spain: UNWTO.

Dwyer, L. (2015b). Computable general equilibrium modelling: An important tool for tourism policy analysis. Tourism and Hospitality Management, 21(2), 111-126.

Dwyer, L., \& Forsyth, P. (1993). Assessing the benefits and costs of inbound tourism. Annals of Tourism Research, 20(4), 751-768.

Dwyer, L., \& Forsyth, P. (2009). Public sector support for special events. Eastern Economic Journal, 35(4), 481-499.

Dwyer, L., \& Forsyth, P. (2017). Event evaluation: Approaches and new challenges. In E. Lundberg, J. Armbrecht, T. D. Andersson, \& D. Getz (Eds.), The value of events (pp. 105-123). London, UK: Routledge.

Dwyer, L., Forsyth, P., \& Spurr, R. (2004). Evaluating tourism's economic effects: New and old approaches. Tourism Management, 25(3), 307-317.

Dwyer, L., Forsyth, P., \& Spurr, R. (2005). Estimating the impacts of special events on the economy. Journal of Travel Research, 43(4), 351-359.

Dwyer, L., Forsyth, P., \& Spurr, R. (2006). Assessing the economic impacts of events: A computable general equilibrium approach. Journal of Travel Research, 45(1), 59-66. doi: https://doi.org/10.1177/0047287506288907

Dwyer, L., Jago, L., \& Forsyth, P. (2016). Economic evaluation of special events: Reconciling economic impact and cost-benefit analysis. Scandinavian Journal of Hospitality and Tourism, 16(2), 115-129.

Farrow, S., \& Rose, A. (2018). Welfare analysis: Bridging the partial and general equilibrium divide for policy analysis. Journal of Benefit-Cost Analysis, 9(1), 67-83.

Fleischer, A., \& Felsenstein, D. (2002). Cost-benefit analysis using economic surpluses: A case study of a televised event. Journal of Cultural Economics, 26(2), 139-156.

Forsyth, P. (2006). Tourism benefits and aviation policy. Journal of Air Transport Management, 12, 3-13.

Frechtling, D. C., \& Horvath, E. (1999). Estimating the multiplier effects of tourism expenditures on a local economy through a regional input-output model. Journal of Travel Research, 37(4), 324-332.

Fuguitt, D., \& Wilcox, S. J. (1999). Cost-benefit analysis for public sector decision makers. Westport, CT: Quorum Books. Greenwood Publishing Group, Inc.

Getz, D. (2017). Developing a framework for sustainable event cities. Event Management, 21(5), 575-591.

Hayashi, T. (2017). General equilibrium foundation of partial equilibrium analysis. London, UK: Palgrave Macmillan.

Jago, L., \& Dwyer, L. (2006). Economic evaluation of special events: A practitioners' guide. Altona, Australia: Common Ground Publishers. 
Just, R. J., Hueth, D. L., \& Schmitz, A. (2004). The welfare economics of public policy: A practical guide to policy and project evaluation. Cheltenham, UK: Edward Elgar Publishing.

Kesanne, S. (2005). Do we need an economic impact study or a cost-benefit analysis of a sport event? European Sport Management Quarterly, 5(2), 133-142.

Kwiatkowski, G. (2016). Economic impact of event attendees' spending on a host region: A review of the research. Event Management, 20(4), 501-515.

Li, S., Blake, A., \& Thomas, R. (2013). Modelling the economic impact of sports events: The case of the Beijing Olympics. Economic Modelling, 30, 235244.

Madden J. (2006). Economic and fiscal impacts of mega sporting events: A general equilibrium assessment. Public Finance and Management, 6(3), 346-394.

Maguire, K., \& Hanrahan, J. (2017). Assessing the economic impact of event management in Ireland: A local authority planning perspective. Event Management, 21(3), 333-346.
Matheson, V. (2002). Upon further review: An examination of sporting event economic impact studies. The Sport Journal, 5(1), 1-7.

Ministry of Business Innovation and Employment. (2013). Economic evaluation outcomes: Major events development fund: Meta-evaluation report. Wellington, New Zealand: Ministry of Business, Innovation \& Employment. Retrieved from https:/www.majorevents.govt.nz/assets/ Major-Events/63bcd1bf67/MEDF-evaluation-report.pdf

Richards, G., \& Colombo, A. (2017). Special issue: Rethinking the eventful city. Event Management, 21(5), 527-634.

Shaffer, M., Greer, A., \& Mauboules, C. (2003). Olympic costs and benefits. A cost-benefit analysis of the proposed Vancouver 2010 Olympic and Paralympic Games. Canadian Centre for Policy Alternatives Publication. Retrieved from https:// www.policyalternatives.ca/sites/default/files/uploads/ publications/BC_Office_Pubs/olympics_costbenefit.pdf

Victorian Auditor General Office. (2007). State investment in major events. Victoria, Australia: Victorian Government Printer. Retrieved from https://www.parliament. vic.gov.au/papers/govpub/VPARL2006-10No14.pdf 